\title{
Dental Health Knowledge, Attitudes and Behaviour among Students at the Kuwait University Health Sciences Centre
}

\author{
R. Al-Hussaini ${ }^{a}$ M. Al-Kandari ${ }^{a} \quad$ T. Hamadi ${ }^{a}$ A. Al-Mutawa ${ }^{a}$ S. Honkala ${ }^{b}$ \\ A. Memon ${ }^{a}$ \\ Faculties of a Medicine and ${ }^{b}$ Dentistry, Health Sciences Centre, Kuwait University, Kuwait
}

\section{Key Words}

Toothbrushing · Sugar - Subjective dental health • University students · Medicine • Pharmacy • Dentistry • Kuwait

\begin{abstract}
Objective: The aim of the study was to determine the extent of dental health knowledge among students at the Kuwait University Health Sciences Centre (HSC), as well as their attitudes toward dental health and their oral hygiene habits. Methods: A structured questionnaire was distributed to 450 of the 800 students enrolled in 3 faculties of the HSC from March to April 2000. The questionnaire was completed anonymously by the students. Results: Four hundred and ten students (91.1\%) completed the questionnaire. Of these, $64.6 \%$ believed that the main cause of tooth decay was 'not brushing properly'. Only $19.3 \%$ of the students believed that sugar could cause dental decay. Half of the students did not know if sugar-free drinks are harmful to their teeth, and $29.5 \%$ did not know about any measures to prevent gums from bleeding. Self-assessment questions showed that $84.5 \%$ of the students were satisfied with their dental health. A large majority of the students $(94.8 \%)$ brushed their teeth at least once a day. Female students brushed their teeth
\end{abstract}

\section{KARGER}

Fax +41613061234

E-Mail karger@karger.ch

www.karger.com

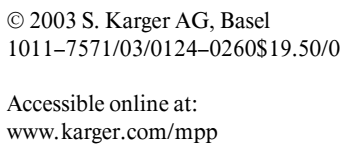

more frequently than male students, as did those students who had visited a dentist in the past 6-12 months and those who rated their dental health to be very good. The main reason given for a dental visit was toothache (70.0\%). Coffee was consumed daily by $68.9 \%$ of students, $76.6 \%$ of whom added sugar to their coffee. Conclusions: The findings indicate that although most of the students at the HSC seem to be satisfied with their dental health, they did not have correct knowledge about the causes and prevention of dental diseases. In general, female students were more aware and concerned about dental health issues and more engaged in dental behaviour than male students.

Copyright $@ 2003$ S. Karger AG, Basel

\section{Introduction}

Oral health habits are measures people learn and practice regularly in order to maintain good oral health or prevent oral disease. The most common oral diseases, dental caries and periodontal disease, are considered to be behavioural diseases because adoption of healthy oral habits is crucial in controlling them. Traditionally, good oral health practice consists of continuous implementation of 2 broadly defined sets of behaviour: self-care habits (den- 
tal hygiene, restriction of sugar products, use of fluoride products) and utilization of dental services (regular dental examinations, oral health education, and professionally applied preventive measures) [1].

Many methods are available for maintaining optimal oral hygiene, among which toothbrushing is the most widely accepted method for the prevention and control of periodontal diseases [2, 3]. Most researchers recommend toothbrushing twice a day and agree that when performed with fluoride toothpaste, it could also reduce dental caries [4-7]. However, a recent systematic review of the available evidence has shown that toothbrushing plays a limited role in caries prevention [8], because brushing alone is not sufficient in cleaning the proximal surfaces of teeth. As such, using dental floss is therefore also recommended to further help in preventing both dental caries and periodontal disease $[9,10]$. Limiting the consumption of sugar-containing foods is also important in preventing periodontal disease and tooth decay. Added sugar (two thirds of which comes from confectionery, table sugar, and soft drinks) poses the greatest threat to dental health [11] Sucrose is the primary source of energy for certain bacteria and helps them multiply, form plaque and produce acid that is harmful to dental enamel and dentin [12].

Toothbrushing, the use of fluoride products, dietary practices and other behaviour relating to oral health depend on value and belief systems and vary from culture to culture. For instance, the desire to restrict sugar is more strongly related to body image and perceived overweight than to dental caries risk [13]. In Kuwait, few studies [1416] have been conducted on oral health behaviour, and hence little information on this topic is available.

The aim of this study was to determine the extent of dental health knowledge among students at the Kuwait University Health Sciences Centre (HSC), as well as their attitudes toward dental health and oral hygiene habits.

\section{Subjects and Methods}

This cross-sectional study was conducted from March to April 2000, among students at the Faculties of Medicine, Pharmacy and Dentistry at the Kuwait University HSC. The students were approached in the classrooms, HSC lobby, reading rooms and cafeteria, and were asked to anonymously fill out a structured questionnaire which addressed the following aspects: (a) socio-demographic characteristics (age, gender, marital status, faculty affiliation, study year, nationality, and perceived financial status of the family); (b) knowledge, attitudes and perceptions concerning dental health, and (c) dental health habits (toothbrushing, flossing, use of mouthwash, regularity of dental visits, and consumption of sugar-containing and sugarfree products).

Dental Health Behaviour among Kuwaiti

University Students
Of the 800 students enrolled in the 3 faculties during the academic year 1999/2000, 450 were approached for participation in the study. The study included 287 out of 612 students from the Faculty of Medicine, 94 out of 138 from the Faculty of Pharmacy and 29 out of 50 from the Faculty of Dentistry, giving a total of 410 responses. Students who were not included in the study were at other locations of the university or different hospitals during the data collection period.

The data were analysed using the statistical software SPSS for Windows version 10.0. The $\chi^{2}$ test was used to examine the association between two categorical variables; the Student $t$ test was used to compare between the means of two continuous variables, and the normal $\mathrm{Z}$ test was used to assess the difference between two proportions. A $p$ value of $<0.05$ was used as a cut-off level for statistical significance. The multiple logistic regression analysis was performed to study the factors independently associated with the toothbrushing frequency. Odds ratios (OR) and their confidence intervals (95\% CI) were estimated.

\section{Results}

\section{Characteristics of the Study Population}

The age of the HSC students ranged between 15 and 29 years, with a mean age of $21.4 \pm 2.7$ years. There were more female than male students in the sample (63.9 vs. $36.1 \%$ ), reflecting the gender distribution of the students at the HSC. One tenth $(10.7 \%)$ of the students were married ( $12.2 \%$ of the female students and $8.1 \%$ of the males). Regarding family income, $51.5 \%$ reported that their family was financially well off, $34.9 \%$ were about average, and the rest thought that they were not well off. The majority of the students (70.0\%) were at the Faculty of Medicine, since the Faculties of Pharmacy and Dentistry had only recently been established and therefore had relatively fewer enrolled students. The response rate for this study was $91.1 \%$.

\section{Knowledge and Attitudes/Perceptions concerning Dental Health}

Of the students from the 3 faculties, $64.5 \%$ believed that the main cause of tooth decay was 'not brushing properly', $19.3 \%$ thought that sugar could cause dental decay, while $10.2 \%$ of the students believed that weak enamel is the main cause. Half of the students did not know if sugar-free or diet drinks are harmful to their teeth. Almost one third (29.5\%) of the students did not know of any measure that could prevent gums from bleeding, and $30.7 \%$ thought that going to the dentist for a check-up would be the best option. More boys (20.3\%) than girls $(9.2 \%)$ thought that toothbrushing could prevent gums from bleeding. The percentage of students who thought that gingival bleeding could be prevented 
Table 1. Advice received by the HSC students on issues related to dental health

\begin{tabular}{lcccc}
\hline & Male & Female & Total & p value \\
\hline Have you ever received advice on & & & & \\
Brushing teeth & $101(68.2)$ & $139(53.1)$ & $240(58.5)$ & $<0.01$ \\
Times you should visit dentist & $60(40.5)$ & $112(42.7)$ & $172(42.0)$ & $\mathrm{NS}$ \\
Use of toothpaste & $71(48.0)$ & $98(37.4)$ & $169(41.2)$ & $<0.05$ \\
Use of mouthwash & $63(42.6)$ & $90(32.4)$ & $154(37.3)$ & $\mathrm{NS}$ \\
Caring for your gums & $51(34.5)$ & $96(36.6)$ & $147(35.9)$ & $\mathrm{NS}$ \\
Diet for good dental health & $35(23.6)$ & $87(32.2)$ & $122(29.8)$ & $<0.05$ \\
Use of floss & $36(24.3)$ & $57(25.6)$ & $103(25.1)$ & $\mathrm{NS}$ \\
None of the above & $27(18.2)$ & $51(19.5)$ & $78(19.0)$ & $\mathrm{NS}$ \\
\hline Where did you get this advice? & & & & \\
Dentist/dental nurse & $75(50.7)$ & $170(64.9)$ & $245(59.8)$ & $<0.01$ \\
Magazine/newspaper & $61(41.2)$ & $137(52.3)$ & $198(48.3)$ & $<0.05$ \\
TV/radio & $71(48.0)$ & $120(48.8)$ & $191(48.4)$ & $\mathrm{NS}$ \\
Family/friends & $80(54.1)$ & $105(40.1)$ & $185(45.1)$ & $<0.01$ \\
Teacher & $48(32.4)$ & $74(28.2)$ & $122(29.8)$ & $\mathrm{NS}$ \\
School nurse & $35(23.6)$ & $63(24.0)$ & $98(23.9)$ & $\mathrm{NS}$ \\
Pharmacist & $6(4.1)$ & $4(1.5)$ & $10(2.4)$ & $\mathrm{NS}$ \\
\hline
\end{tabular}

NS $=$ Not significant. Figures in parentheses indicate percentages. by removing plaque or by using dental floss was 7.3 and $2.4 \%$, respectively.

With regard to personal assessments of dental health, $38.5 \%$ of the students rated their dental health very good, $46.1 \%$ satisfactory and $15.3 \%$ reported that it could be better. The students who thought that their family was well off considered their dental health to be better than did those from families of average or below-average incomes $(\mathrm{p}<0.001)$. The majority $(60.0 \%)$ of the students were satisfied with the appearance of their teeth, $25.1 \%$ had mixed feelings, and $14.8 \%$ were not satisfied. Almost all of the students (94.1\%) felt that they are directly responsible for their dental health, and $61.2 \%$ believed that if they look after their teeth they would last for a lifetime. However, about one third thought that a dentist is also responsible for looking after their teeth. There was no gender nor age difference in these perceptions.

The main reasons for looking after teeth among both genders were to avoid toothache and dental treatment (28.0\%), to look nice $(22.0 \%)$, and to feel clean $(18.5 \%)$. When students were asked if they had been advised about different oral health habits, $19 \%$ responded that they had not received any kind of guidance mentioned in the list. Boys received advice mostly from family/friends (54.1\%) and dentist/dental nurse $(50.7) \%$, while girls received advice from dentist/dental nurse $(64.9 \%)$ and the media $(52.3 \%)$. The most common advice was related to toothbrushing (boys $68.2 \%$, girls $53.1 \%$; $\mathrm{p}<0.01$ ) (table 1 ).

\section{Dental Health Habits}

It was found that $94.7 \%$ of the students brushed their teeth at least once a day. Twice-a-day toothbrushing was more common among girls than among boys (79.7 vs. $46.6 \%, p<0.001)$. Students from well-off families reported a greater brushing frequency than those from average or less well-off families $(\mathrm{p}<0.05)$. There was a clear association between toothbrushing frequency and subjective dental health $(\mathrm{p}<0.01)$; those who reported very good dental health brushed more often $(76.4 \%)$ than those reporting good $(66.1 \%)$ or not very good dental health $(50.8 \%)$.

In the logistic regression analysis, the following factors were independently associated with toothbrushing more than once a day: gender (OR 4.6; 95\% CI 2.80-7.69), visiting a dentist during the last $6-12$ months (OR 2.8; 95\% CI 1.68-4.81), and the personal assessment of dental health (OR 2.3; 95\% CI 1.14-4.46) (table 2). The students rarely used oral hygiene methods other than toothbrushing. Only $14.6 \%$ of the students reported daily use of mouthwash, and $11.5 \%$ regular use of dental floss. About a quarter of the students did not know about flossing.

Coffee was consumed daily by $68.9 \%$ of students, $76.6 \%$ of whom added sugar to their coffee. Sugar-free or diet drinks were consumed by only $18.5 \%$ of the students, and about half of the students (52.9\%) never chose those drinks.

Of all the students in the study, $43.7 \%$ visited a dentist only when there was a real need, while $22.0 \%$ of the stu- 
Table 2. Factors associated with the more-than-once-a-day toothbrushing frequency among HSC students

\begin{tabular}{lll}
\hline Factor & OR & $95 \%$ CI \\
\hline Gender & & \\
$\quad$ Male & 1.0 & \\
$\quad$ Female & 4.6 & $2.80-7.69$ \\
Faculty & & \\
$\quad$ Medicine & 1.0 & \\
$\quad$ Pharmacy & 0.9 & $0.51-1.65$ \\
$\quad$ Dentistry & 2.1 & $0.56-7.82$ \\
Family well-off & & \\
$\quad$ Not well-off & 1.0 & \\
$\quad$ Average & 2.1 & $0.59-7.22$ \\
$\quad$ Well-off & 1.9 & $0.56-6.60$ \\
Personal assessment of dental health & & \\
$\quad$ Could be better & 1.0 & \\
$\quad$ Good & 2.3 & $1.14-4.46$ \\
$\quad$ Very good & 2.9 & $1.31-6.48$ \\
Appearance of teeth & & \\
$\quad$ Not satisfied & 1.0 & \\
$\quad$ Mixed feelings & 2.2 & $1.06-4.77$ \\
$\quad$ Satisfied & 1.2 & $0.58-2.42$ \\
Dental visits & & \\
$\quad$ Only when needed & 1.0 & \\
$\quad$ 6-12 months & 2.8 & $1.68-4.81$ \\
$\quad$ More than 2 years & 2.0 & $0.72-5.73$ \\
\hline
\end{tabular}

dents visited a dentist at least once in 6 months and almost the same proportion (21.5\%) at least once a year. The main reasons for dental visits were toothache (70.0\%), teeth cleaning (46.6\%), and dental check-up (31.7\%). Female students visited dentists to get their teeth cleaned more often than male students (51.5 vs. $37.8 \%$; $\mathrm{p}<0.01)$. The majority of the students $(62.9 \%)$ did not feel nervous about a dental visit.

\section{Discussion}

This is the first study to determine the knowledge of dental health and the practice of oral health habits among students at the Kuwait University HSC, and as such, some reservations in interpreting the results of this study are noted. Most students were from the Faculty of Medicine because the Faculties of Pharmacy and Dentistry had only recently been established. In addition, the number of respondents from the Faculties of Pharmacy and Dentistry was lower than that from the Faculty of Medicine due to the 2 programs' low annual admissions. Despite these reservations, this study forms a baseline description of oral health behaviour of medical, pharmacy and dental students, which can be compared with a later study to establish possible trends and differences between various entering classes. Since the response rate was high (91.1\%), non-response bias does not impact the findings, and some conclusions can be confidentially drawn.

The importance of toothbrushing was the most common advice given concerning oral health, consistent with some previous studies [17-19], and toothbrushing was more commonly believed to prevent dental decay than to prevent bleeding gums, although the reverse is true [6]. Only a relatively small proportion (19.3\%) of the students thought that sugar is the main cause of dental caries. The results of a study among Kuwaiti mothers [15] showed that the majority was aware of the importance of brushing but needed more information about the importance of avoiding sugar and the protective effect of fluoride in preventing dental decay. Nevertheless, mothers were more aware than students at the HSC about the role of sugar in dental caries and the effectiveness of toothbrushing in the prevention of bleeding gums.

Schoolteachers seemed to have even more accurate knowledge than both mothers and students at the HSC about the causes and prevention of dental decay and bleeding of gums [15]. It has been shown that teachers play an important role in promoting good oral health behaviour, and dental health education at schools has a considerable effect on children [20]. However, it appears that teachers in Kuwait do not give enough advice or devote sufficient time to discuss oral health (table 1). In some countries, schools provide special oral health education (OHE) programs that are conducted annually by dental staff of health centres. For instance, OHE lessons have had a positive effect on oral health and habits among 18year-old Finns [17]. We therefore recommend that the Kuwaiti school systems institute similar OHE lessons in schools.

Most of the students tended to be satisfied with their own dental health and the appearance of their teeth, which may partly explain why most of them visited a dentist only when they felt a real need and not for regular examinations. This finding is similar to that reported in a national survey conducted in 1985 , in which Kuwaitis aged 15-29 years had visited a dentist during the previous 12 months most often for toothaches [16]. In a study among university students in Italy, almost $60 \%$ had visited a dentist during the previous 12 months for a check-up [21], a much larger number than in this study (43.7\%), probably because HSC students visited dentists only when they had a real need to. Although dental check-ups 
every 6 months are commonly recommended in many countries, there is no scientific evidence to justify this high frequency of dental visits, which can sometimes lead to unnecessary dental treatment [22, 23-26]. In Nordic countries, annual check-ups have been advocated, but there is a recommendation to increase the interval [27], and as a result an individually determined recall interval based on assessment of caries risk is becoming more common $[28,29]$.

In Kuwait, the School Oral Health Program provides dental treatment for children between 6 and 12 years of age, but no recall system for regular dental check-ups has been implemented [30]. After the age of 12 years, children visit dentists based on need and personal initiative. In a study conducted among 12-year-old schoolchildren in Kuwait, about half visited a dentist only when they had problems with their teeth or gums, and $15 \%$ were called for a further appointment by the dentist [14]. The fact that young people in Kuwait are not used to visiting a dentist on a regular basis in their childhood and during the adolescent years might be another explanation for the low attendance at dental offices reported in this study. In Finland, all young people under the age of 19 years are entitled to free dental check-ups and dental care by the Public Dental Health Services, and 95\% of adolescents between 12 and 18 years of age visit a dentist at least every second year [27]. In addition, the Student Health Service provides dental check-ups and dental care without cost for all college students in their first, third and fifth years of study [31]. There is a clear need to establish a regular dental check-up program in Kuwait for children, adolescents and young adults, to prevent dental diseases and to provide accurate information about oral disease and their prevention.

In this study, $67.6 \%$ of the students brushed their teeth more than once a day, compared with $92.1 \%$ in Italy [21]. In Norway, Austria, Germany, Denmark, and Sweden, $73-83 \%$ of children as young as 11 years old brushed more often than once a day [32]. Females at the HSC followed the recommended toothbrushing frequency more often than males, which is consistent with results from studies conducted in other countries [3, 32-35]. The proportion of individuals who brushed at least once a day in this study (94.7\%) was much higher than in the nationally representative survey conducted in 1985 (76.1\%) [16], perhaps because students at the HSC are more healthoriented than the general population, as would be expected. The students who brushed more than once a day reported better dental health than those who brushed less often. Consistent with the findings of a large international study [32], dental floss was rarely used as a component to maintain good oral hygiene; $25.4 \%$ of the students at HSC did not know about dental floss.

The percentage of students who drank coffee with sugar is similar to the proportion of Kuwaiti mothers who drink tea with sugar several times per day (70\%) [15]. About half of the Finnish adolescents reported the daily use of sugar in coffee [19]. In a recent study among 12year-old Kuwaitis, 74\% consumed sugar-containing soft drinks, $64 \%$ drank milk with sugar, and $40 \%$ drank tea with sugar [14]. A similarly high rate of soft drink consumption was found among 11-year-olds in Northern Ireland, Scotland and the Slovak Republic [36]. Sugar-containing products seem to be a common risk for dental health in Kuwait, and knowledge and use of sugar-free or diet drinks is low according to this study.

These findings indicate that there is much work to be done in health education to establish healthy behaviour among students at the HSC. As future health professionals, these students should have a good amount of knowledge about health and its determinants and adopt healthy behaviour, since they will be expected to be role models for their patients and the community at large.

\section{Conclusions}

Most of the students at the Kuwait University HSC visited a dentist only when there was a real need, and check-up appointments were uncommon. The advice they most often received concerned toothbrushing, and the majority of the students brushed their teeth according to accepted recommendations. Sugar-containing coffee was used regularly and sugar-free or diet drinks very rarely. In general, female students at the HSC were more aware and concerned about dental health issues and more engaged in dental behaviour than male students. Although most of the students seemed to be satisfied with their dental health, they did not have correct knowledge about the causes and the prevention of dental caries and periodontal diseases.

\section{Acknowledgements}

We are grateful to Dr. Eino Honkala (Department of Developmental and Preventive Sciences, Faculty of Dentistry) for his valuable guidance in the planning and conducting of this study. Mrs. Ajitha Suresh provided excellent help in data entry and analysis. Our warmest thanks go to the Medical, Pharmacy and Dental students who participated in the study. 


\section{References}

1 Honkala E: Oral health promotion with children and adolescents; in Schou L, Blinkhorn AS (eds): Oral Health Promotion. New York, Oxford University Press, 1993, pp 169-187.

2 Sheiham A: Dental cleanliness and chronic periodontal disease. Studies on populations in Britain. Br Dent J 1970;129:413-418.

3 Addy M, Dummer PMH, Hunter ML, Kingdon A, Shaw WC: The effect of toothbrushing frequency, toothbrushing hand, sex and social class on the incidence of plaque, gingivitis and pocketing in adolescents: A longitudinal cohort study. Community Dent Health 1990;7:237247.

4 Suomi JD: Prevention and control of periodontal disease. Review of dental research. J Am Dent Assoc 1971;83:1271-1287.

5 Frandsen A: Mechanical hygiene practices. State-of-the-science review; in Löe $\mathrm{H}$, Kleinman DV (eds): Dental Plaque Control Measures and Oral Hygiene Practices. Washington, IRL Press Ltd, 1986, pp 93-116.

6 Ainamo J: Relative roles of toothbrushing, sucrose consumption and fluorides in maintenance of oral health in children. Int Dent $\mathrm{J}$ 1980;30:54-66.

7 Dummer PMH, Oliver SJ, Hicks R, Kingdon A, Kingdon R, Addy M, Shaw WC: Factors influencing the caries experience of a group of children at the ages of $11-12$ and 15-16 years Results from an ongoing epidemiological survey. J Dent 1990;18:18-20.

8 Reisine ST, Psoter W: Socioeconomic status and selected behavioural determinants as risk factors for dental caries. J Dent Educ 2001;65: 1009-1016.

9 WHO: Prevention of Disease. Geneva, WHO, Offset publication No 103, 1987.

10 American Dental Association: Wake up to prevention for the smile of lifetime. Guide to dental health. J Am Dent Assoc 1988;16:3G, 6G$13 \mathrm{G}$.

11 Rugg-Gunn A, Lennon MA, Brown JG: Sugar consumption in the United Kingdom. Br Dent J 1986;161:359-363.

12 Johansson I, Birkhed D: Diet and the caries process; in Thylstrup A, Fejerskov O (eds) Textbook of Clinical Cariology. Copenhagen, Munksgaard, 1994, pp 283-299.
13 Honkala E, Eskola A, Rimpelä M, Rajala M: Consumption of sweet foods among adolescents in Finland. Community Dent Oral Epidemiol 1982;10:103-110.

14 Vigild M, Petersen PE, Hadi R: Oral health behaviour of 12-year-old children in Kuwait. Int J Paediatr Dent 1999;9:23-29.

15 Petersen PE, Hadi R, Al-Zaabi FS, Hussein JM, Behbehani JM, Skougaard MR, Vigild M: Dental knowledge, attitudes and behaviour among Kuwaiti mothers and school teachers. J Pedod 1990;14:158-164.

16 Behbehani JM, Shah N: Oral health in Kuwait before the Gulf War. Med Princ Pract 2002; 11(suppl 1):36-43.

17 Laiho M, Honkala E, Nyyssönen V, Milen A: Recall and perception of oral health education among 18-year-olds. Health Educ Res 1991;6: 43-48.

18 Honkala S, Honkala E, Tynjälä J, Kannas L: Oral health habits of Finnish- and Swedishspeaking schoolchildren and received instructions (in Finnish, English summary). Finn Dent J 2000;5:202-205.

19 Honkala S, Honkala E, Rimpelä A, Vikat A: Oral hygiene instructions and dietary sugar advice received by adolescents in 1989 and 1997. Community Dent Oral Epidemiol 2002;30: 124-132.

20 Glasrud P, Frazier P: Future elementary schoolteachers' knowledge and opinion about oral health and community programs. J Public Health Dent 1988;48:74-80.

21 Rimondini L, Zolfanelli B, Bernardi F, Bez C: Self-preventive oral health behavior in an Italian university student population. J Clin Periodontol 2001;28:207-211.

22 Sheiham A: Is there a scientific basis for sixmonthly dental examination? Lancet 1977; ii:442-444.

23 Elderton RJ: Six monthly examinations for dental caries. Br Dent J 1985;158:370-374.

24 Elderton RJ, Nuttall NM: Variation among dentists in planning treatment. Br Dent J 1983; 154:201-206.
25 Nuttall NM, Davies JA: Dental attendance behaviour of children in Scotland between 1983 and 1988. Br Dent J 1992;172:378-382.

26 Elderton RJ: Overtreatment with restorative dentistry: When to intervene? Int Dent J 1993; 43:17-24.

27 Honkala E, Kuusela S, Rimpelä A, Rimplelä M, Jokela J: Dental services utilization between 1977 and 1995 by Finnish adolescents of different socioeconomic levels. Community Dent Oral Epidemiol 1997;25:383-390.

28 Nordblad A, Suominen-Taipale L, Rasilainen $\mathrm{J}$ : Oral health care in Finnish health centers in 1991 (in Finnish). Publications of the Nationa Agency of Welfare and Health, Reports 115 , Helsinki, 1993.

29 Wang N, Marstrander P, Holst D, Ovrum L, Dahle T: Extending recall intervals - Effect on resource consumption and dental health. Community Dent Oral Epidemiol 1992;20:122124

30 Al-Mutawa S, Al-Duwairi Y, DePoala PF Udani TM, Soparkar PM: A comprehensive dental survey of Kuwaiti schoolchildren. First Kuwait Assoc Dent Res Meet, abstract book, Kuwait, April 2001, p 28

31 Turtola L: Systematic dental health care among Finnish university students. Proc Finn Dent Soc 1991;87:637-642.

32 Kuusela S, Honkala E, Kannas L, Tynjälä J: Oral hygiene habits of 11-year-old schoolchildren in 22 European countries and Canada in 1993/1994. J Dent Res 1997;76:1602-1609.

33 Macgregor IDM, Balding JW: Toothbrushing frequency and personal hygiene in 14-year-old schoolchildren. Br Dent J 1987;162:141-144.

34 Træen B, Rise J: Dental health behaviours in a Norwegian population. Community Dent Health 1990; 7:59-68

35 Honkala E, Karvonen S, Rimpelä A, Rajala M, Rimpelä M, Prättälä R: Oral health promotion among Finnish adolescents between 1977 and 1989. Health Promot Int 1991;6:21-30.

36 Kuusela S, Kannas L, Tynjälä J, Honkala E, Tudor-Smith C: Frequent use of sugar products by schoolchildren in 20 European countries, Israel and Canada in 1993/1994. Int Dent J 1999;49:105-114. 